\title{
APONTAMENTOS SOBRE A EDUCAÇÃO PROFISSIONAL NO NORTE DO PARANÁ: HISTÓRIA DO SENAC DE MARINGÁ (1955-1982)
}

\author{
Notes on profession education in Northern Paraná: Senac de Maringá's \\ history (1955 -1982)
}

\section{Notas sobre educación profesional en el Paraná del Norte: historia del Senac de Maringá (1955-1982)}

Amanda Marconi* $^{*}$
Analete Regina Schelbauer* $^{*}$
Simone Burioli Ivashita* $^{*}$

\section{Resumo}

O presente artigo tem como objetivo tecer apontamentos e reflexões em torno da educação profissional em Maringá, cidade situada na região Norte do Paraná, a partir da pesquisa que teve como foco o olhar para a história e a memória institucional do Serviço Nacional de Aprendizagem Comercial (Senac). Neste sentido, analisaremos aspectos da identidade cultural desta instituição educativa e, para tanto, aborda-se o processo histórico de criação, institucionalização e consolidação da instituição, com a finalidade de compreender quais as motivações que possibilitaram sua criação e seu percurso no município, gerando a expansão da instituição no Estado do Paraná. A delimitação temporal abrange o período de 1955, ano que o Senac inicia suas atividades em Maringá e se estende até 1982, período em que a pesquisa ofereceu indícios de sua consolidação. $\mathrm{O}$ artigo busca contribuir com o campo de estudos e pesquisas sobre a história da educação, suas instituições educativas e, mais especificamente, para a preservação da história e da memória do Senac.

PALAVRAS-CHAVE: Serviço Nacional de Aprendizagem Comercial (Senac). Educação Profissional. História das Instituições Educativas. Maringá-Paraná

\begin{abstract}
This article aims to make notes and reflections on vocational education in Maringá, a city located in the northern region of Paraná, based on research that focused on the

\footnotetext{
* Mestre em Educação pela Universidade Estadual de Maringá (UEM). Gerente Executiva do SENAC Paraná. Email:amanda.marconi@pr.senac.br. Orcid: https://orcid.org/0000-0002-1406-3622

* Doutora em Educação pela Universidade de São Paulo. Professora do Departamento de Teoria e Prática da Educação e do Programa de Pós-Graduação em Educação da Universidade Estadual de Maringá (UEM). Email: analeteregina@gmail.com. Orcid: https://orcid.org/0000-0003-2466-6360

* Doutora em Educação pela Universidade Estadual de Maringá (UEM). Professora do Departamento de Educação da Universidade Estadual de Londrina( UEL). Email: sivashita@ yahoo.com.br. Orcid: https://orcid.org/ 0000-0002-8766-8331
} 
history and institutional memory of the National Service for Commercial Learning (Senac). In this sense, it seeks to analyze aspects of the cultural identity of this educational institution and, therefore, addresses the historical process of creation, institutionalization and consolidation of the institution, in order to understand what motivations enabled its creation and its path in the municipality, generating the expansion of the institution in the state of Paraná. The temporal delimitation covers the period of 1955, the year in which SENAC begins its activities in Maringá and extends until 1982, when the research provided evidence of its consolidation. The article seeks to contribute to the field of studies and research on the History of Education, its educational institutions and, more specifically, for the preservation of SENAC's History and Memory.

KEYWORDS: National Service for Commercial Learning (Senac). Professional Education. History of Educational Institutions. Maringá-Paraná

\section{Resumen}

Este artículo tiene como objetivo tomar notas y reflexiones sobre la educación profesional en Maringá, una ciudad ubicada en la región norte de Paraná, basada en una investigación que se centró en la historia y la memoria institucional del Servicio Nacional de Aprendizaje. Comercial (Senac). En este sentido, analizaremos aspectos de la identidad cultural de esta institución educativa y, por lo tanto, se aborda el proceso histórico de creación, institucionalización y consolidación de la institución, para comprender las motivaciones que permitieron su creación y su trayectoria en la ciudad, generando La expansión de la institución en el estado de Paraná. La delimitación temporal abarca el período comprendido entre 1955, año en que Senac comienza sus actividades en Maringá y se extiende hasta 1982, cuando la investigación proporcionó evidencia de su consolidación. El artículo busca contribuir al campo de estudios e investigaciones sobre la historia de la educación, sus instituciones educativas y, más específicamente, la preservación de la historia y la memoria de Senac.

PALABRAS CLAVE: Servicio Nacional de Aprendizaje Comercial (Senac). Educación Profesional. Historia de las Instituciones Educativo. Maringá-Paraná

\section{INTRODUÇÃO}

Este artigo tem como tema a história institucional do Serviço Nacional de Aprendizagem Comercial (Senac) de Maringá, e objetiva tecer apontamentos e reflexões em torno do desenvolvimento da educação profissional em Maringá, cidade situada na região Norte do Paraná, no período de 1955 a 1982. A pesquisa que deu origem ao presente texto situa-se no campo da história das instituições educativas, vinculada à linha história e historiografia da educação. O artigo teve como foco o olhar para a história e a memória institucional do Serviço Nacional de Aprendizagem Comercial (Senac) e analisar as relações entre trabalho e educação profissionalizante a partir da instituição educativa compreendida em seu contexto histórico.

A investigação é justificada pela necessidade de contribuir com a preservação da história e da memória das instituições educativas no município maringaense, e pela 
relevância social que a instituição representou para a comunidade e a cultura local. Neste artigo, começamos abordando o contexto social, político e econômico em que o Senac foi constituído.

A importância de pesquisar a história de uma instituição é ampla, pois, conforme Buffa (2002), a pesquisa acerca das instituições escolares é um jeito de estudar a história e a filosofia da educação brasileira, uma vez que as instituições que compõem os sistemas escolares estão impregnadas pelos valores de cada época.

A história do Senac de Maringá oferece conhecimentos sobre as relações sociais mais amplas, os sistemas educativos e acerca dos impactos das políticas educativas no âmbito institucional. Por isso, analisamos o contexto econômico e político do Estado e da cidade onde o Senac foi criado, bem como o desenvolvimento da educação profissional no período.

Metodologicamente, adotamos a pesquisa documental e bibliográfica como caminho para realização desta investigação. Conforme Nunes (2006, p. 197), essas fontes "são materiais produzidos e utilizados na própria instituição escolar que se está estudando; são importantes fontes primárias". Como fontes documentais, utilizamos decretos, ementas, leis, acervo iconográfico (fotografias), jornais, documentos da própria instituição (relatórios anuais de gestão) e, como fonte bibliográfica, para embasar e dar subsídio teórico à pesquisa pautamo-nos em autores que abordam os temas instituições educativas e escolares, educação profissional e sobre a constituição da cidade de Maringá.

Consideramos que para a construção da história de uma instituição educativa é importante estudar seus arquivos, seus documentos institucionais e as pessoas envolvidas na cultura dessa escola. Para tanto, fizemos um levantamento bibliográfico sobre pesquisas já realizadas sobre a educação profissional contemplando especificamente a palavra "Senac" dentro da área de conhecimento educação. Encontramos duas teses de doutorado, 18 dissertações de mestrado e nove artigos. Desses, apenas uma dissertação de mestrado que contemplou a história da instituição Senac.

A dissertação referida foi desenvolvida no Programa de Pós-graduação em Educação da Universidade Federal de Uberlândia, de autoria de Graciane Gomes Santana, orientada por Vera Lucia Abrão Borges. O título é A reconstrução Histórica do Senac de Uberlândia - MG (1954-1974), defendida em 2007, cujo objetivo foi reconstruir a gênese, a formação e a consolidação do Senac na cidade de Uberlândia, MG.

\section{A educação profissional no Brasil: um olhar histórico}

Neste momento analisamos as transformações dos processos educativos e de qualificação profissional, instituídos no período histórico entre 1955 a 1982. Desta forma, empreendemos uma trajetória desse ensino no país e no Estado do Paraná, porque, para compreender o nosso objeto de estudo, precisamos entender o contexto histórico geral do momento em que ele foi criado. 
A educação profissional é baseada no modelo de produção taylorista ${ }^{1}$ e segue dotada do racionalismo técnico, que é presente em toda a sua metodologia. Nela há preocupação com a seleção do conteúdo, direcionada a formar mão de obra produtiva e qualificada para o trabalho conforme os interesses econômicos e as leis capitalistas do local onde se encontram inseridas.

Machado (1982) afirma que o ensino técnico está mais voltado para a aplicação prática dos princípios do que para sua teorização. Na educação profissional e no ensino técnico há aquisição de conhecimentos mais práticos do que teóricos, propiciando uma adesão maior do mercado de trabalho.

Para aprofundar a compreensão do histórico da educação profissional no Brasil, é necessário retomar a trajetória desse ensino no país. Na década de 1940, com a promulgação e aprovação das Leis Orgânicas do Ensino, também denominadas de Reforma Capanema, extinguiram-se os cursos complementares criados pela Reforma Francisco Campos, em 1932, e nesse contexto o ensino profissional ganha espaço. Segundo Saviani (2008), apesar de reformas parciais, como a Reforma Capanema, a estrutura educacional foi reorganizada e as reformas foram estabelecidas mediante oito decretos leis, quais sejam:

a) Decreto-lei $\mathrm{n}^{\circ} 4.048$, de 22 de janeiro de 1942, que criou o Senai (BRASIL, 1942a);

b) Decreto-lei no 4073, de 30 de janeiro de 1942, que criou a Lei Orgânica do Ensino Industrial (BRASIL, 1942b);

c) Decreto-lei $n^{\circ} 4.244$, de 9 de abril de 1942, Lei Orgânica do Ensino Secundário (BRASIL, 1942d);

d) Decreto-lei no 6.141, de 28 de dezembro de 1943, Lei Orgânica do Ensino Comercial (BRASIL, 1943b);

e) Decreto-lei ${ }^{\circ}$ 8.529, de 2 de janeiro de 1946, Lei Orgânica do Ensino Primário (BRASIL, 1946e);

f) Decreto-lei no 8.530, de 2 de janeiro de 1946, Lei Orgânica do Ensino Normal (BRASIL, 1946a);

g) Decreto-lei $\mathrm{n}^{\circ}$ 8.621, de 10 de janeiro de 1946, que criou o Senac (BRASIL, 1946b);

h) Decreto-lei no 9.613, de 20 de agosto de 1946, Lei Orgânica do Ensino Agrícola (BRASIL, 1946d).

A Reforma Capanema, conforme Saviani (2008), promoveu uma série de mudanças no ensino. Em relação à educação profissional, ela foi subdividida em industrial, comercial e agrícola, além do normal. Este autor pondera que "[...] o caráter da Reforma era centralista, burocratizado, e dualista, separando o ensino secundário, destinado às elites condutoras do meio de produção, do ensino profissional, direcionado ao povo, conduzido à execução do trabalho" (SAVIANI, 2008, p. 269), concedendo ao ramo secundário o acesso a qualquer carreira de nível superior. Ele a caracteriza como corporativista, visto que vinculava estreitamente cada ramo ou tipo de ensino às profissões e aos ofícios requeridos pela organização social.

Santos (2000) acrescenta que a reforma elevou a educação profissional ao grau de ensino médio e estabeleceu uma dicotomia para esse nível de ensino: o ensino

\footnotetext{
${ }^{1}$ Taylorismo é uma expressão particular de um mesmo fenômeno: o controle do processo de trabalho pela dinâmica da acumulação capitalista. Sobre o tema, ver mais em: PINTO, G. A. A organização do trabalho no século 20: taylorismo, fordismo e toyotismo. 2. ed. São Paulo: Expressão Popular, 2010.
} 
secundário com a finalidade de formar uma sólida cultura geral e o ensino profissional para formar trabalhadores. Cunha (1977), por seu turno, reforça que o ensino médio profissional encontraria sua essência na necessidade de combater a frustração dos seus concluintes que não conseguissem ou não quisessem ingressar em cursos superiores.

Machado (1982) sustenta que a Reforma Capanema consolidou a estrutura elitista do ensino brasileiro e institucionalizou duas organizações paralelas, com objetivos, aparelhagem e domínios próprios. $\mathrm{O}$ ensino secundário, destinado a preparar as individualidades condutoras, e o ensino profissional, direcionado para formar mão de obra qualificada para as necessidades do sistema produtivo.

Nesse contexto, o ensino industrial assumiu um relevante papel na formação da mão de obra, sobretudo na industrialização do país. Ante tal importância e sem recursos públicos para promover a expansão do ensino técnico-industrial, o governo "[...] transfere sua responsabilidade pela formação profissional das classes menos favorecidas ao setor privado" (NASCIMENTO, 2011, p. 24).

Diante desse cenário, em 1942, ocorreu a criação do Senai pelo decreto-lei $\mathrm{n}^{\circ}$ 4.048 , de 22 de janeiro de 1942, como assinalamos, e do Senac pelos decretos-lei $\mathrm{n}^{\circ}$ 8.621 e $\mathrm{n}^{\mathrm{o}}$ 8.622, de 10 de janeiro de 1946, instituições de educação profissional organizadas e geridas pelos organismos patronais. A criação dessas instituições foi considerada pela sociedade como uma importante ação integrada à reforma, propiciando às instituições sustentáculo e o seguimento da mesma linha de pensamento, evidenciando a relevância atribuída naquele momento histórico do país para a mão de obra especializada.

Gomes (2013) destaca que a criação dessas duas instituições, Senai e Senac, foram para atender à demanda de qualificação para o trabalho em todos os níveis de profissionalização, cujo intuito era de capacitar, de forma rápida, um número maior de pessoas para os setores de produção imediatos.

Abordando sobre a criação do Sistema S, como dito anteriormente, esse sistema foi criado pelo governo federal na década de 1940 por meio de leis e decretos, esse delega às instituições a obrigação de ministrarem, em cooperação com o Estado, a aprendizagem de ofícios, cursos e formações para o trabalho dentro das normas estabelecidas pelo sistema nacional de ensino. Segundo Manfredi (2002), atualmente, o grupo que constitui o Sistema S, inclui o Senac e outras oito instituições - Sesc, Senai, Sesi, Senar, Senat, Sest, Sebrae e Sescoop.

Os estudos e as negociações para a criação do Senac e do Senai, realizados nesse período, foram fruto da influência da Constituição de 1937 e da política de incentivo ao crescimento da indústria e do comércio. Para Fausto (2013), o interesse do governo Vargas em promover a indústria refletia-se diretamente na educação, e, embora o ministro Capanema havia promovido uma reforma no ensino secundário, sua maior preocupação consistia em organizar o ensino industrial com o objetivo principal de capacitar o menor operário.

Conforme Furini (2007), em maio de 1945, “os empresários do comércio reuniram-se em Teresópolis, no Rio de Janeiro, para um exame dos problemas da economia nacional na Conferência das Classes Produtoras do Brasil". Um dos resultados mais importantes dessa conferência foi a divulgação do documento "Carta da Paz Social", que recomendava ao governo federal, dentre outras, medidas para atenuar a complexidade crescente das funções especializadas na área mercantil e sugeria a 
intensificação e o aperfeiçoamento do ensino médio e superior do comércio, além do estímulo à criação de escolas.

Essa carta selou o que daria origem ao Senac e ao Serviço Social do Comércio $(\mathrm{Sesc})^{2}$. Essas instituições promovem ações que ajudam o desenvolvimento do setor terciário do país e da sociedade, sendo o Senac focado em educação profissional e o Sesc em saúde, cultura, esporte e lazer.

Destacamos que, na década de 1940, havia necessidade de entidades regulamentadoras e articuladoras dos interesses do comércio para o desenvolvimento do país. Assim, em 1945, foi fundada a Confederação Nacional do Comércio (CNC), reconhecida pelo decreto federal $\mathrm{n}^{\circ}$ 20.068, de 30 de novembro de 1945 (BRASIL, 1945), entidade representativa nacional dos direitos e interesses do comércio brasileiro, que, posteriormente, criaria o Senac.

Em 1946, o presidente Eurico Gaspar Dutra baixou os decretos-lei $n^{0} 8.621$ e ${ }^{0}$ 8.622, que autorizavam a CNC instalar e administrar, em todo o país, escolas de aprendizagem comercial para trabalhadores menores, entre 14 e 18 anos, bem como cursos de continuação e especialização para comerciários adultos. Dessa forma, de acordo com Santana (2007, p. 46), foi

[...] delegada à CNC a responsabilidade de estruturar e administrar, em âmbito nacional, escolas de aprendizagem comercial para funcionários e interessados em conquistar emprego no comércio". Criava-se, assim, o Senac, sua finalidade direciona-se para a qualificação profissional de adultos e formação de jovens aprendizes, sediado na capital federal (Rio de Janeiro) e descentralizado por meio de Conselhos Regionais e Departamentos Regionais em cada um dos estados da União.

Com o passar do tempo, influenciado pelo desenvolvimento econômico, político e social do país, pelo incentivo à industrialização, ao crescimento e ao fomento do comércio, o Senac passou a oferecer educação profissional em larga escala, destinada à preparação e à formação de mão de obra de trabalhadores para o comércio.

Em síntese, a atuação do Senac consiste em atender à empresa comercial e ao trabalhador do comércio, com mão de obra qualificada para trabalhar nesse ofício, seja ofertando formação ao jovem aprendiz, seja proporcionando cursos rápidos ou de longa duração realizados na própria instituição ou em instituição parceira com os cursos em cooperação ${ }^{3}$.

\footnotetext{
${ }^{2} \mathrm{O}$ Senac e o Sesc são organizados e administrados pelo mesmo órgão, a Confederação Nacional de Comércio de Bens, Serviços e Turismo (CNC), órgão máximo de representação sindical patronal de setores fundamentais para a economia brasileira. Os recursos utilizados para a manutenção do Sesc e do Senac vêm do recolhimento compulsório sobre a folha de pagamento das empresas, conforme definido pelo decreto-lei $n^{\circ}$ 9.853/1946, Sesc e decreto-lei $n^{\circ} 8.621 / 1946$, Senac: $1,5 \%$ para o Sesc e $1 \%$ para o Senac. Recolhidos, via Receita Federal, os recursos constituem "dinheiro carimbado", necessários ao custeio de ações de interesse público por isso requerem auditorias do poder público (SESC/BR, 2016). ${ }^{3}$ Cursos em cooperação são os cursos do Senac ofertados em instituições parceiras. No início, os acordos em cooperação eram firmados com escolas de comércio, na maioria particulares, que ofereciam a infraestrutura necessária para o funcionamento dos cursos, como aparelhamento escolar, corpo docente e direção dos cursos. O Senac era responsável pelos programas, orientação pedagógica, apoio financeiro e fiscalização do processo, "à medida que o projeto de expansão do Senac vai ganhando forma, expandindo-se e sendo implantado ensino próprio por todo o país entra em declínio esse tipo de parceria em meados das décadas de 1960 a 1970”. (SENAC/BR, 2006, p. 14).
} 
Retomando ao contexto da época, na década de 1970, a fase do governo tecnocrata e a preocupação com a internacionalização da economia brasileira acarretouse uma tendência tecnicista à educação. Surge a lei no 5.692/71 - LDB (Lei de Diretrizes e Bases da Educação) - "com a proposta da ampliação nos anos de estudo para o primeiro e o segundo graus, sendo a profissionalização integrada, na tentativa de eliminar o dualismo educacional até então existente" (SANTANA,2007). Desta forma, torna-se obrigatória para o segundo grau a qualificação profissional, cujo objetivo era seu caráter terminal, em que grande contingente de alunos pudesse sair do sistema escolar mais cedo e ingressar o quanto antes no mercado de trabalho. Gomes (2013) propala que esse movimento também diminuiria a procura pelo ensino superior, portanto, como a maioria das pessoas que chegava ao ensino médio era barrada nesse nível, a educação continuava excludente.

$\mathrm{Na}$ concepção de Cunha (1989), a educação profissional passou a ter grande importância no período da ditadura militar ${ }^{4}$, por ser entendida como uma maneira de resolver problemas estruturais graves como o desemprego. Este deixaria de ser um problema estrutural e complexo da economia e se transformaria em uma carência; o subemprego deixaria de existir, eliminando mais uma barreira à igualdade de oportunidades no país.

Em 1982, com a lei $n^{\circ} 7.044 / 82$, se extingue no nível formal a escola única de profissionalização obrigatória e a tentativa de se criar uma escola unitária que aproximasse o mundo do trabalho ao mundo da escola para todos (BRASIL, 1982). A lei $\mathrm{n}^{\circ}$ 5.692/71 tentou uma integração entre esses dois mundos, entretanto, conforme Nosella (1998), eles não se integraram, havendo a continuidade do sistema dual e excludente, visto que, desde as Leis Orgânicas de Capanema, passando pela LDB de 1961, essa foi a única lei que tentou relacionar a educação de elite (focada no preparo para o vestibular e o ensino superior) à educação popular (de caráter terminal e tecnicista).

A tentativa da educação com objetivos sociais, políticos e pedagógicos na formação de sujeitos plenos e capacitados para o trabalho não ocorreu como se esperava e ficou restrita à tentativa de se suprir as necessidades específicas imediatas do mercado de trabalho. Assim sendo, apesar de a educação buscar uma aproximação entre o mundo do trabalho com a sala de aula, nos anos 1980, do ensino médio, a preparação imediata e exclusiva para o mercado de trabalho foi descartada.

\section{O Senac de Maringá: criação, institucionalização e consolidação de uma educação profissional}

Ao pesquisar sobre o histórico do Senac de Maringá, verificamos que há poucos registros sobre a sua história. Abordaremos o início da instituição no Estado paranaense até o momento da sua criação na cidade de Maringá.

No Paraná, o primeiro Senac foi fundado na capital, no dia 07 de julho de 1947, com o fito de suprir a demanda de mão de obra qualificada pelos municípios paranaenses em consonância com os preceitos da lei orgânica vigente. Nesse dia, o ato

\footnotetext{
${ }^{4}$ Segundo Sabbi (2014), a burguesia estava associada ao poder militar e a lei $n^{\circ} 5.692 / 1971$, ao estabelecer uma mesma estrutura de ensino médio para todos, contrariava os interesses dessa classe que era a favor da educação profissional de nível médio, mas não para seus filhos. Por isto, a lei perdurou somente até 1982 quando foi criada a lei $n^{\circ} 7.044 / 1982$, extinguindo a obrigatoriedade da profissionalização.
} 
solene de criação do Senac Paraná foi realizado na sede da Associação Comercial do Paraná, Curitiba-Paraná. A primeira Delegacia Estadual, como era denominada a atual Direção Regional, foi instalada em seguida no edifício João Prosdócimo, na praça Tiradentes (BOLETIM, 2015).

Nesse período, enquanto na capital paranaense construía-se o projeto do novo edifício da Administração Regional do Senac, na rua André de Barros, no interior, os cursos se multiplicavam em cidades como Londrina, Foz do Iguaçu, Apucarana, Cornélio Procópio, Paranaguá, Prudentópolis, Maringá, Toledo, Umuarama, Palotina, Irati, Nova Esperança, Pato Branco, Siqueira Campos, Santo Antônio da Platina, Cambé, Cascavel, Jacarezinho, Paranavaí, Rio Negro, União da Vitória, Campo Mourão e Palmas eram atendidas pelas unidades móveis (kombis-equipadas com elementos de sala de aula que permitia ao Senac realizar seus cursos) e por parcerias realizadas entre Senac e entidades da cidade.

Em Maringá, o Senac iniciou suas atividades em 1955 dentro das instalações do Ginásio Estadual de Maringá com a realização de um curso de Prática de Comércio. De 1955 a 1959, apenas duas turmas foram formadas, totalizando 54 matrículas. A década de 1960 foi marcada pela realização de 23 turmas, com 725 matrículas (JORNAL, 1982). Nesse período, o Senac era parceiro e funcionava nas instalações da Associação Comercial e Empresarial de Maringá - ACIM.

No que se refere à produção e matrículas, com a pesquisa, identificamos que houve um salto de matrículas no Senac de Maringá na década de 1970, com 786 turmas, totalizando 19.134 matrículas, especialmente nos cursos de datilografia, auxiliar de escritório, cabeleireiro, manicuro e outros da área de vendas e saúde (JORNAL, 1982). Esse crescimento se deve ao convênio feito com a ACIM, visto que, em consonância com Silva e Gomes (2016), a parceria entre as duas instituições transformou a associação em um núcleo de ensino profissionalizante no ano de 1972.

Essa parceria se estendeu até 1973, quando o Senac se fixou oficial e provisoriamente em um prédio alugado, na avenida Parigot de Souza, $\mathrm{n}^{\circ}$ 554, como um minicentro de formação profissional, que, em 1977, depois de ampliar seu portfólio de cursos e seu número de atendimento, passou a Centro de Formação Profissional (BACICHETI, 1982).

Em 1977, a Prefeitura Municipal de Maringá fez a doação do terreno na avenida Colombo, zona 07, para a construção da sede própria do Senac, dando apoio financeiro para a obra. A construção iniciou-se em 1979 e ficou pronta em 1982, sendo inaugurada precisamente em 29 de abril de 1982, passando a ser o Centro de Desenvolvimento Profissional de Maringá, assim considerado por ser sede própria da instituição. O Senac tornou-se, então, mais conhecido e suas programações alcançaram a população que se preocupava em se preparar para o mercado de trabalho.

As instalações da unidade chamaram atenção pela arquitetura, pelo tamanho, por ser na época a maior obra em seu gênero construída no interior do Brasil, mas, notavelmente, pela serventia em prol da dinamização do treinamento $\mathrm{e}$ profissionalização de mão de obra para setores diversos da cidade, especialmente o terciário. João Paulino Vieira Filho, o prefeito da época, relatou que "A comunidade de Maringá e a Administração Municipal, sentem-se honradas em sediar a maior obra do Senac no interior do Brasil, completando uma grande estrutura para a formação profissional dos maringaenses" (JORNAL, 1982, p. 8). 
A nova sede contava com as empresas pedagógicas, restaurante, lanchonete, confeitaria e instituto de beleza-escola, que passaram a atender a clientela da cidade e dos municípios vizinhos. No período, "o Centro de Desenvolvimento Profissional de Maringá foi ampliado e, com ele, aumentou o número de funcionários, passando a ser de 69 pessoas para conseguir suprir o contingente atendido pelo Senac" (JORNAL, 1982, p. 5).

No início da década de 1980, o Senac de Maringá já atendia a 90 municípios, assegurando a uma população calculada em mais de 1 milhão a possibilidade de melhor formação profissional, além de atender à classe empresarial, do comércio e de serviços. Os cursos oferecidos pelo Senac de Maringá, na década de 1980, abarcavam diversas áreas do conhecimento, os quais permitiam aos alunos um itinerário formativo, ou seja, possibilitavam que eles planejassem sua carreira em uma perspectiva de educação continuada. Sobre a gestão da unidade, em 1984, assumiu a direção, Bonifácio Suzuki, que permaneceu no cargo até agosto de 1985. Em seguida, assumiu Edwin Parascandalo, ficando à frente da Unidade de Educação Profissional (UEP) de Maringá de $1^{\circ}$ de outubro de 1985 a 30 de junho de 2003. Após esse período, o Senac de Maringá passou a ser dirigido por Antonio Carlos Aroca, que, até o presente momento de escritura deste trabalho, é gestor desta unidade.

\section{Organização pedagógica no Senac de Maringá no período entre 1950 a 1982}

Neste item, vamos apresentar a organização pedagógica do Senac no período estudado. Segundo o livro denominado Senac 60 anos, publicado em comemoração à existência sexagenária desta instituição, as modalidades de ensino ofertadas por ele em seu início no país, em 1946, e em sua instituição em Maringá, no ano de 1955, foram:

\footnotetext{
[...] adaptação, para menores que eram candidatos a emprego no comércio; aprendizagem, para menores de 14 a 18 anos, a praticantes do comércio, dividido em três modalidades: curso elementar, curso para praticantes e curso de preparação funcional;

continuação ou Práticos de Comércio, cujo público-alvo seriam comerciários adultos, divididos em três modalidades: curso fundamental, curso de habilitação e curso intensivo; especialização, para ampliação de conhecimentos adquiridos noutros cursos (SENAC/BR, 2006, p. 15).
}

Na década de 1960, o Senac passou por diversas mudanças e sofreu influências da lei $n^{\circ} .4 .024$ de 1961, a primeira Lei de Diretrizes e Bases da Educação Nacional. Esta lei trouxe uma nova forma de pensar a educação profissional e, no que se refere ao Senac, influenciou na mudança de perfil da clientela, passando de menores para adultos. Na década de 1970, as mudanças trazidas pela LDB 5692/71 impactaram diretamente o modo do Senac realizar seu ensino, visto que essa lei instituiu o sistema de ensino brasileiro em cursos de primeiro e segundo graus e supletivo, e privilegiou um enfoque bastante profissionalizante.

Para se adequar à nova lei, de acordo com Marconi (2017) o Senac se empenhou em elaborar uma reformulação curricular, com o intuito de possibilitar a habilitação regular e a qualificação intensiva de sua clientela composta de adolescentes e, sobretudo, de adultos. Passou ainda a oferecer, em regime de complementaridade, formação profissional a alunos do sistema regular de ensino. Para atender aos novos 
rumos da educação nacional, a instituição promoveu uma revisão de suas diretrizes gerais, aprovadas em 1973, oferecendo cursos nas seguintes modalidades: aprendizagem, qualificação, habilitação, seminários e programas de treinamento para empresas. (SENAC/ BR, 2006 p.20).

Essas modalidades se mantiveram até 2001 quando sofreram influências da LDB 9.394/96, ao propor que as instituições de ensino criassem seu próprio projeto políticopedagógico (SENAC/BR, 2006). Segundo o Projeto político-pedagógico/PR (PPP)(SENAC/PR, Administração Regional, 2007) com o passar do tempo, o Senac de Maringá passou a oferecer cursos com as seguintes características de ensino: presencial, semipresencial e a distância.

Com a análise das fontes, identificamos que o Senac de Maringá, durante o período estudado, acompanhou a trajetória pedagógica desenvolvida e promovida pela instituição em todo território brasileiro. Percebemos que durante o período estudado, houve modificações no contexto pedagógico da instituição, mudanças relacionadas com a preocupação de entregar uma formação alinhada com as demandas do mercado de trabalho, que se apresentava cada vez mais exigente e crescente.

\section{CONSIDERAÇÕES FINAIS}

Nesse momento, faz-se importante salientar que a reconstrução da história do Senac de Maringá, proposta nesse artigo, ocorreu por meio de fontes e investigações que permitiram a interpretação do passado dessa instituição pelas lentes do pesquisador. Um olhar que não teve a intenção e nem possibilidade de esgotar o assunto, deixando várias aberturas para novas pesquisas, bem como para críticas e questionamentos.

Mediante a pesquisa desenvolvida, foi possível responder o questionamento que se intentava saber: "Quais as motivações para a criação, institucionalização e consolidação do Senac na cidade de Maringá, Paraná?” A hipótese que se levantou foi de que as motivações para todo o desenvolvimento do Senac de Maringá foram fomentadas pelo fortalecimento, crescimento e rumos tomados pelo comércio maringaense que demandava mão de obra qualificada e especializada para suprir suas demandas.

A pesquisa permitiu que se analisassem as transformações do processo educativo e de qualificação profissional dentro do período no qual foi proposto o estudo. Outro aspecto que se destacou neste estudo foi que o ensino ofertado pelo Senac acompanhou as mudanças propostas pelas LDBs, por isso, ao analisar suas modalidades, verificamos que eram tomados os decretos - leis $\mathrm{n}^{\circ} 4.024 / 1961$ e $\mathrm{n}^{\circ}$ 5.692/1971 - como marco e, à medida que se propunham mudanças para a educação profissional nacional, o impacto era/é direto na forma do Senac fazer educação.

Espera-se que este artigo contribua com o campo de pesquisas acerca das instituições educativas, sobretudo, para a educação profissional maringaense. Além disso, que as considerações realizadas sirvam de estímulo para novas pesquisas sobre esta instituição e seu papel para a educação profissional no Brasil.

\section{REFERÊNCIAS}


BACICHETI, Marta. Abordagem sobre a contribuição do Senac na Formação de Obra de Maringá 1979-1980. 100f. 1982 (Trabalho de Conclusão de Curso) - Universidade Estadual de Maringá, Maringá, PR, 1982.

BOLETIM. Fecomércio, junho de 2015. Disponível em: $<$ http://www.fecomerciopr.com.br/publication/boletim-especial-senac-68anos/wppa_open/> Acesso em: 04 dez. 2018.

Decreto-Lei $n^{o}$ 20.068, de 30 de novembro de 1945. Reconhece a Confederação Nacional do Comércio. Rio de Janeiro, RJ: Câmara Legislativa, 1945. Disponível em:<http://www2.camara.leg.br/legin/fed/decret/1940-1949/decreto-20068-30novembro-1945-480483-publicacaooriginal-1-pe.html>. Acesso em: 04 dez. 2018.

Decreto-lei $n .^{o} 8.621$, de 10 de janeiro de 1946. Dispõe sobre a aprendizagem dos comerciários, estabelece deveres dos empregadores e dos trabalhadores menores relativamente a essa aprendizagem e dá outras providências. Rio de Janeiro, RJ: Governo Federal, 1946b. Disponível em:<http://www2.camara.leg.br/legin/fed/declei/1940-1949/decreto-lei-8621-10janeiro-1946-416555-norma-pe.html>. Acesso em: 4 dez. 2018.

Decreto-lei $n .^{\circ} 8.622$, de 10 de janeiro de 1946. Dispõe sobre a criação do Serviço Nacional de Aprendizagem Comercial e dá outras providências. Rio de Janeiro, RJ: Governo Federal, 12 jan. 1946c. Disponível em:<http://www.planalto.gov.br/ccivil_03/decreto-lei/1937-1946/Del8622.htm>Acesso em: 4 dez. 2018.

Decreto-lei $n .^{\circ} 4.024$, de 20 de dezembro de 1961. Lei de Diretrizes e Bases da Educação Nacional - Fixa as Diretrizes e Bases da Educação Nacional. Brasília, DF: Governo Federal, 14 de dezembro de 1962. Disponível em<http://www.planalto.gov.br/ccivil_03/LEIS/L4024.htm>: Acesso em: 4 dez. 2018.

. Decreto-lei $n^{\circ}{ }^{7} 7044 / 82$, de 18 de outubro de 1982. Altera dispositivos da Lei $\mathrm{n}^{\circ}$ 5.692, de 11 de agosto de 1971, referentes à profissionalização do ensino de $2^{\circ}$ grau.Brasília, DF: Governo Federal, 1982. Disponível em:<http://www.planalto.gov.br/ccivil_03/LEIS/L7044.htm>. Acesso em: 4 dez. 2018.

BUFFA, Ester. Os estudos sobre instituições escolares: organização do espaço e propostas pedagógicas. In: NASCIMENTO, Maria Isabel. Moura et al. (Orgs.). 130 Instituições escolares no Brasil: conceito e reconstrução histórica. Campinas, SP: Autores Associados; HISTEDBR; Sorocaba, SP: Uniso; Ponta Grossa, PR: UEPG, 2002. p. 151- 163.

CUNHA, Luiz Antonio Rodrigues da. Política Educacional no Brasil: a profisssionalização do Ensino Médio. 2. ed. Rio de Janeiro: Eldorado,1977.

Educação e desenvolvimento social no Brasil. 11. ed. Rio de Janeiro: Francisco Alves, 1989. 
FAUSTO, Boris. A História do Brasil. 14. ed. São Paulo: Edusp, 2013.

FURINI, Isabel. Desafios e triunfos: Senac Paraná 60 anos. Curitiba: SENAC PR, 2007.

GOMES, Helica Silva Carlos. Os modos de organização e produção do trabalho e a educação profissional no Brasil: uma história de dualismos e racionalidade técnica. In: MULLER, Meire Terezinha; BATISTA, Eraldo Leme (Orgs.). A educação profissional no Brasil: Campinas, SP: Alínea, 2013. p. 59-81.

Jornal O diário de Maringá, de 29 de abril de 1982, Maringá, PR, 1982.

MACHADO, Lucíliade Souza. Educação e divisão social do trabalho: contribuição do ensino técnico industrial brasileiro. São Paulo: Cortez, 1982.

MANFREDI, Silvia Maria. Educação profissional no Brasil. São Paulo: Cortez, 2002.

MARCONI, Amanda. História do SENAC Maringá: um estudo sobre Educação Profissional no Norte do Paraná (1955-1982). Dissertação (Mestrado em Educação) Universidade Estadual de Maringá, Maringá, PR, 2017.

NASCIMENTO, Manoel Nelito. História, trabalho e educação no Brasil: os primórdios da educação profissional. Germinal: Marxismo e Educação em Debate, Londrina, PR, v. 3, n. 2, p. 15-25, dez. 2011.

NOSELLA, Paolo. A escola brasileira no final do século: um balanço. In: FRIGOTTO, Gaudencio (Org.). Educação e crise do trabalho: perspectivas de final de século. Petrópolis, RJ: Vozes, 1998.

NUNES, Antonietta d' Aguiar. Fontes para a História da Educação. Práxis educacional, v. 2, p. 187-206, 2006.

SABBI, Volmir. Políticas Educacionais no Brasil a dualidade educacional nas trajetórias de escolarização e profissionalização. Tese (Doutorado em Educação) Universidade Estadual de Maringá, Maringá, PR, 2014.

SANTANA, Graciane. Gomes. A reconstrução histórica do Senac de Uberlândia-MG: (1954 - 1974). 2007. Dissertação (Mestrado em Educação) - Universidade Federal de Uberlândia, Uberlândia, MG, 2007.

SANTOS, Jailson Alves dos. A trajetória da educação profissional. In: LOPES, et al. (Org.). 500 anos de Educação no Brasil. 2. ed. Belo Horizonte: Autêntica, 2000.p. 205224.

SAVIANI, Demerval. Histórias das ideias pedagógicas no Brasil. 2. ed. Campinas, SP: Autores Associados, 2008.

SENAC/BR. Senac 60 anos. Rio de Janeiro: Departamento Nacional, 2006. 
Relatório de Gestão referente ao ano de 1951. Curitiba: Administração Regional, 1951.

Projeto Político Pedagógico do Senac Paraná. Curitiba: Administração Regional, 2007.

SILVA, Miguel. Fernando. Peres.; GOMES, Dirceu. Herrero. A solidez de um legado. Maringá: Sinergia, 2016.

Recebido em: 20/10/2019

Aprovado em: 18/12/2019 